\title{
Desvelando conceitos: a questão das substâncias psicoativas
}

\author{
Unveiling concepts: the issue of \\ psychoactive substances
}

Marlene Barreto Santos Miranda

Autora para correspondência. Escola Bahiana de Medicina e Saúde Pública (Salvador). Bahia, Brasil. marlenemiranda@bahiana.edu.br

O presente editorial tem como objetivo discutir alguns aspectos relacionados à problemática das drogas através de uma postura compreensiva que relativize "as demonizações radicais das substâncias". ${ }^{1}$ Não se discute "drogas" em termos de seus efeitos sobre a saúde, tema que conta com relativa literatura especializada, respaldando diversas perspectivas e que pediria aporte médico-científico relacionado a diferentes tipos de substâncias. A intenção é explorar o discurso sobre drogas hoje e a confusão presente na abordagem ancorada no senso comum que termina por obscurecer sentidos, bem como viabiliza a possibilidade de o lugar das drogas ser um construto social destes tempos.

O tema drogas é um dos mais presentes nos meios de comunicações, infelizmente nem sempre tratado com a devida sobriedade, nem com o embasamento científico, sociológico e cultural desejáveis.

É importante que, inicialmente, se conceitue o principal termo utilizado nesse artigo, já que, quando tratado pela mídia e presente no nosso dia a dia, é mal definido ou pouco claro. Assim, droga, segundo Milby², é toda substância, natural ou sintética, que, ao ser consumida, atua sobre o sistema nervoso central (cérebro), modificando, de algum modo, nosso psiquismo. Estão incluídas aí todas as substâncias legais ou lícitas (álcool, tabaco, medicamentos, café e chá) e todas as substâncias ilegais ou ilícitas (maconha, cocaína, heroína, crack, inalantes, alucinógenos).

Em nossa sociedade, o termo droga deixou de ter uma significação puramente científica, aparecendo geralmente relacionado às substâncias ilegais ou ilícitas e associado a comportamentos transgressores, como coloca Nery Filho ${ }^{3}$, o que leva a distinguir dois níveis de compreensão distintos: o primeiro, que define droga segundo critérios técnico-científicos precisos, e o segundo, mais largo, menos preciso, que considera droga em função de certas características ideológicas, às vezes em completo desacordo com a própria realidade sociocultural. Nesse artigo, a palavra droga terá como sinônimo o termo substância psicoativa e será usada exclusivamente no sentido descrito no primeiro nível acima.

A expressão substância psicoativa foi proposta pela Organização Mundial de Saúde - OMS, para substituir o termo droga, geralmente de conotação-pejorativa, englobando toda substância, natural ou sintética que, ao ser consumida, altera uma ou mais funções do organismo. 
Ao percorrermos a história da civilização, encontramos a presença das substâncias psicoativas desde os primórdios da humanidade, inseridas nos mais diversos contextos: social, econômico, medicinal, religioso, ritual, cultural, psicológico, estético, militar e o da busca do prazer.

Já em 1928, um renomado toxicologista francês, Ludwig Lewin, escrevia que, à exceção dos alimentos, não existem sobre a Terra substâncias que tenham estado tão intimamente ligadas à vida dos povos, em todos os países, em todos os tempos, como as substâncias que modificam a percepção humana. ${ }^{4}$

Para afirmar a antiguidade do convívio do ser humano com as substâncias, algumas teorias são apontadas pretendendo demonstrar a presença de bebidas fermentadas na pré-história, bem como na civilização egípcia em que os mais antigos documentos da civilização egípcia descrevem o uso do vinho e da cerveja. A literatura científica dá conta de que o opium já era conhecido mais de cinco mil anos antes de Cristo e relacionado com a alegria e divertimento entre os sumérios. Os egípcios, por sua vez, conheciam o cânhamo (maconha) e outras substâncias com propriedades narcóticas e tóxicas. $\underline{5}$

Diferente dos contextos citados ("anos rebeldes", ampliação da percepção, usos ritualísticos, experiências místicas, busca do prazer), a realidade atual tem outras motivações para o consumo de substâncias psicoativas e formas próprias de normatizá-la, domesticá-la ou reprimi-la. Falar sobre drogas virou um modismo, tanto por parte das autoridades, que têm o dever de estabelecer programas para repressão do tráfico de substâncias psicoativas ilícitas, prevenir o uso abusivo de SPA a lícitas e também ilícitas e propiciar tratamentos de usuários dependentes, quanto para a população em geral, que possui um conhecimento recheado de estereótipos e preconceitos sobre as SPAs.

O enfoque repressivo é o mais presente na sociedade, atendo-se exclusivamente ao produto "drogas", considerando como único fator responsável pelo alastramento do consumo e das toxicomanias. No entanto, não se torna toxicômano quem o quer, há um processo complexo em que intervém, além da substância psicoativa, o contexto sociocultural e econômico, com suas pressões, condicionamentos múltiplos e a personalidade do usuário.

"[...] a toxicomania é o encontro de uma pessoa com um produto psicoativo num determinado momento sócio-cultural". De uma forma mais ampliada, o momento sociocultural é representado pela cultura e condições do país ou região; numa visão mais específica, essas condições sociais de consumo são as circunstâncias mais restritas em que o consumo se processa: a cidade, o bairro, a rua, o grupo. Com relação à personalidade do usuário, dela fazem parte, as motivações pessoais, conscientes e inconscientes. Somente em casos de uma junção desfavorável desses três fatores da "equação" é que se chega a estados de dependência - o que significa que não é todo consumo que a provoca, pois existem diferentes padrões de consumo e consumidores (experimental ocasional e regular). É necessário perceber esses aspectos para compreender as particularidades do consumo e do consumidor de substâncias psicoativas. ${ }^{-}$

Assim, a percepção/representação que a maioria da população tem acerca das substâncias psicoativas é muito diferente do que efetivamente elas significam. Inúmeras ideias equivocadas estão presentes na nossa sociedade, por exemplo: "é possível ter uma sociedade sem drogas"; "o mal está nas substâncias ilícitas (maconha, cocaína, ácidos, etc.) e não nas ilícitas (álcool, tabaco, medicamentos)"; "a maconha é a porta de entrada para uso de outras substâncias (escalada)", há um forte maniqueísmo expressando que "quem usa drogas é bandido, louco, desajustado"; nas campanhas de prevenção, utilizam-se chavões apelativos - "droga, tô fora", "não quero droga nenhuma" - como se o produto fosse o único responsável pelo aumento do consumo das substâncias psicoativas. ${ }^{-}$

Além de dar uma maior ênfase ao produto, deixando de lado o indivíduo que consome, a associação do uso de substâncias psicoativas à violência é algo fortemente representado na sociedade. Contudo, muitos desses discursos não se apoiam, necessariamente, em fatos presenciados de agressões por usuários. Também são ambíguas as referências que estabelecem nexos entre violência contra terceiros e uso de drogas. Nota-se certa transferência de medos e inseguranças generalizados nesses tempos, quando

${ }^{1} \mathrm{~A}$ abreviatura refere-se à terminologia Substâncias Psicoativas. 
o não controlado, "o estranho" - como as drogas (no caso do uso) - seria considerado a principal causa da insegurança e da violência.

O consumo de substâncias psicoativas não é um fenômeno irresponsável, como a sociedade costuma alardear, e muito menos um fenômeno simples; é uma situação que envolve aspectos psicológicos, biológicos e sociais bem definidos e de grande importância, principalmente para os profissionais da saúde, que deveriam estar capacitados para ofertar ações de promoção à saúde, prevenção dos fatores de risco, assistência aos danos e reabilitação segundo a dinâmica do processo saúde-doença, das pessoas que consomem substâncias psicoativas, para além de estabelecer uma atitude preconceituosa no cuidado.

Outras preocupações pedem reflexão no campo das ciências sociais e da saúde, com o apoio de diversos conhecimentos e, principalmente, atentando para representações de diversos atores que de uma forma ou outra estão envolvidos com substâncias psicoativas: por que do seu uso em termos de compulsão hoje? por que a preocupação com as substâncias psicoativas hoje? quais os sentidos da construção social das "drogas" hoje, sua idealização como costume ou como saída, o seu enquadramento como a violência, o vício, a compulsão, a doença, e, para muitos, a fonte de todos os males?

Não se pretendeu aqui ter respostas acabadas, mas construir uma reflexão sobre possíveis pistas. Defende-se que não atentar para a complexidade do tema - a diversidade de situações e sentidos que diferentes sujeitos emprestam à sua experiência - é uma maneira de evitar análises que mais a fundo nos interroguem a todos, sobre as relações vividas em diferentes instituições e em qual estado da sociedade estamos. Culpando "as drogas", omite-se a cumplicidade de muitos em relações micro e macro-organizadas que alimentam, em muitos casos, mal-estares, buscas existenciais, para alguns o cumprimento de exigências e parâmetros sociais, para outros recusas desses parâmetros, assim como para muitos outros apenas um tipo de comunicação com os outros e consigo, com eus que não conhecemos.
A própria sociedade se "droga" com as "drogas", criando sua toxicomania, buscando escapar, sobretudo, de problemas socioestruturais e culturais mais profundos, assim como de angústias existenciais, como o desemprego, miséria, guerras internas e externas, conflitos geracionais, mudanças velozes na cultura, dentre outras questões. ${ }^{1}$

Pregar a eliminação das substâncias psicoativas da vida social é ingenuidade, se não fanatismo irreal. Trata-se de reduzir os danos, tanto das lícitas quanto das ilícitas. Querer proibi-los, seja pela repressão, seja pela condenação moralista, não surte efeito, pois as substâncias psicoativas fazem parte da vida, inclusive das suas dimensões de valor, como o prazer, o lazer, a busca de sensações novas, idealizadas e a promessa da sociedade de consumo de uma vida sem angústias que leva à obrigatoriedade de ser feliz ou tentar sê-lo, como seja.

As substâncias psicoativas não dão um sentido à vida, mas podem realçar o sentido que cada indivíduo consegue criar para si, principalmente num momento de crise econômica e de sombrias perspectivas sociais em um país como o Brasil; cabe não esquecer isto, para não cair numa pregação repressiva cega e facilmente desumana.

\section{Referências}

1. Minayo MCS, Deslandes SFA. A complexidade das relações entre drogas, álcool e violência. Cadernos de Saúde Pública. 1998;14(1):35-42. https://doi.org/10.1590/S0102311X1998000100011

2. Milby JB. A dependência de drogas e seu tratamento. São Paulo: Pioneira; 1988.

3. Nery Filho A. Drogas: prevenção sem medos e terapia sem estigmas. Salvador: EdUFBA; 1993.

4. Baptista M, Cruz MS, Matias R, organizadores. Drogas e pósmodernidade - prazer, sofrimento, tabu. Rio de Janeiro: EdUERJ; 2003.

5. Bucher R. Drogas e drogadição no Brasil. Porto Alegre: Artes Médicas; 1992. 
6. Olivenstein C. A vida do toxicômano. Rio de Janeiro: Zahar; 1983.

7. Espinheira CGDA. O conhecimento das drogas e suas formas de uso. Pesquisa - Centro de Estudos e Terapia do Abuso de Drogas, UFBA; 1993.

8. Jacobina RR, Nery Filho A. Conversando sobre Drogas. Salvador: EDUFBA; 1999.

9. Kehl MRA. Juventude Como Sintoma da Cultura. In: Novaes R, Vannuchi P, organizadores. Juventude e Sociedade: Trabalho, Educação, Cultura e Participação. São Paulo: Perseu Abramo; 2004.
10. Sarti CA. Algumas Questões sobre Família e Políticas Sociais. In: Jacquet C, Costa LF, organizadores. Família em Mudança. São Paulo: Companhia llimitada; 2004.

11. Soares LE. Juventude e Violência no Brasil Contemporâneo. In: Novaes R, Vannuchi, P, organizadores. Juventude e Sociedade: Trabalho, Educação, Cultura e Participação. São Paulo: Perseu Abramo; 2004.

12. Castro MG, Abramovay M. Drogas nas escolas. Brasília: UNESCO; 2002. 